\title{
A EXPANSÃO DO ENSINO SUPERIOR E A FORMAÇÃO DE PROFESSORES: A PRESENÇA DA SEMIFORMAÇÃO
}

\author{
Raimundo Sérgio de Farias Júnior ${ }^{1}$
}

\section{RESUMO}

$\mathrm{O}$ artigo analisa a recente política de formação de professores no Brasil, via o Programa Nacional de Formação de Professores, tendo por base o conceito de semiformação (particularmente empregado por Theodor Adorno) e é fruto de uma pesquisa realizada junto a docentes de diferentes regiões do Estado do Pará que participaram enquanto discentes do referido Programa pelo curso de Pedagogia (UEPA).

Palavras-chave: Formação de professores. Ensino superior. Expansão do ensino superior. Semiformação. PARFOR.

\section{Resumen}

El artículo analiza la reciente política de formación de profesores en Brasil, veía el Programa Nacional de Formación de Profesores, teniendo por base el concepto de semiformação (particularmente empleado por Theodor Adorno) y es fruto de una investigación realizada junto la docentes de diferentes regiones del Estado del Pará que participaron mientras discentes del referido Programa por el curso de Pedagogía (UEPA).

Palabras clave: La formación de los docentes. Educación superior. Expansión de la educación superior. Semiformação. PARFOR

\section{Introdução}

A semiformação seria a forma social da subjetividade determinada nos termos do capital. É meio para o capital, e simultaneamente, como expressão de uma contradição, sujeito gerador e transformador do capital. Adorno, ao contrário do resignado pessimismo equivocadamente associado sua obra, apresenta uma alternativa prática real para a tendência à totalização social dominante, ao revelar a construção objetiva da formação social presente. Assim, em oposição à fatal "gaiola de ferro" de Max Weber, o viés idealista-ético, que impõe ao indivíduo "uma ordem de coisas inalterável na qual deve viver" (Weber, 1967, p. 34), seria substituído pela perspectiva materialista-dialética de Adorno. Nesta, o que parece ética formal ou cálculo racional se decifra como semiformação pela indústria cultural, que obstrui numa forma social

\footnotetext{
${ }^{1}$ Professor Adjunto da Universidade do Estado do Pará. E-mail: jrbarcafarias@yahoo.com.br

FARIAS JÚNIOR, Raimundo Sérgio de. A expansão do ensino superior e a formação de professores: a presença da semiformação. Revista Sul-Americana de Filosofia e Educação. Número 24: maio-out/2015, p. 232-253.
} 
determinada a contradição material presente em sua determinação social (MAAR, 2003, p. 467).

O presente trabalho é fruto de estudos relacionados a investigações teóricas e empíricas que procuram compreender a expansão da Educação Superior no Brasil à luz dos teóricos da Escola de Frankfurt, em especial Theodor Adorno e seu conceito de semiformação. $\mathrm{O}$ referido texto foi escrito diante de um cenário em que se verifica o crescimento da expansão quantitativa de vagas no Ensino Superior, retrato do caráter neoliberal assumido pelas políticas públicas educacionais implementadas no Brasil a partir da década de 1990. Essa oferta, embora tenha sido muito mais acelerada no âmbito da rede privada, se expandiu também na rede pública, atendendo considerável clientela. No âmbito privado destaca-se a oferta de vagas por meio do PROUNI (Programa Universidade para Todos) e também FIES (Financiamento Estudantil), ambos geridos pelo Governo Federal.

No que concerne especificamente à expansão de vagas em cursos de licenciatura plena na rede pública, percebe-se elevado crescimento por meio do Programa Universidade Aberta Brasil (UAB) e também através do Programa Nacional de Formação de Professores (PARFOR). Dessa forma, entendo que a recente política de formação de professores no Brasil conseguiu, no aspecto quantitativo, atender considerável demanda em razão, sobretudo, da figura do professor leigo ainda existente em nosso país, embora a redução desse tipo de profissional tenha sido alvo de recentes políticas públicas efetivadas com o propósito de eliminar a presença desses nos espaços formais de ensino, em especial na Educação Básica. Não questiono a importância desta expansão tão necessária para alcançar a garantia do direito do acesso à educação pública de qualidade, e sim, a forma como ela ocorre. Indago, nesse texto, especialmente, a dimensão qualitativa dessa formação e questiono até que ponto a forma como tem se dado essa expansão está realmente comprometida com a qualidade de formação inicial e continuada dos docentes que irão atuar ou já atuam na Educação Básica? 
O presente trabalho, tendo por base o conceito de semiformação (particularmente trabalhado por Adorno), é fruto de uma pesquisa empírica realizada junto a docentes de diferentes regiões do estado do Pará que participaram, enquanto discentes, do Programa Nacional de Formação de Professores (PARFOR/UEPA) no curso de Pedagogia. Nesse sentido, apliquei um questionário fechado junto a cursistas do campus de Belém e nos polos de Moju, Marabá e Santarém. Em razão dos dados coletados, senti a necessidade de realizar uma entrevista semiestruturada com alguns dos discentes. Selecionei oito participantes sendo dois de cada polo (quatro homens e quatro mulheres) $e$ cheguei a seguinte configuração: um cursista de Belém, um de Moju, um de Marabá, um de Santarém, um de Castanhal, um de Abaetetuba, um de Rio Maria e um de Belterra. Após a obtenção dos dados escolhi três categorias analíticas: a) formação; b) ensino, pesquisa e extensão; c) qualidade.

A aplicação do questionário permitiu um levantamento inicial de dados de $47^{2}$ (quarenta e sete) discentes, destes 17 (dezessete) eram da turma de Belém, 16 (dezesseis) da turma de Marabá e 14 (catorze) da turma de Santarém. Escolhi esses municípios por pertencerem a regiões distintas de nosso estado e, por ter ministrado a disciplina Didática pelo PARFOR/UEPA, durante os anos de 2012 e 2013, algo que facilitou a realização do processo de coleta de dados. Os resultados serão, a seguir, discutidos e analisados tendo como luz a premissa teórica já anunciada.

\section{Sobre o PARFOR}

O PARFOR, criado ainda na gestão do governo Lula, é um programa de formação emergencial cuja implantação se deu através de uma colaboração entre a CAPES (Coordenação de Aperfeiçoamento de Pessoal de Nível Superior), os Estados, Municípios, Distrito Federal e diversas instituições de Ensino Superior. No campo jurídico o programa nasce por meio do Decreto $n^{\circ} 6.755 / 09$ que instituiu a Política Nacional de Formação de Profissionais do Magistério da Educação Básica. Segundo consta no Inciso III do artigo 11 do Decreto 6.755/09 a CAPES deverá

\footnotetext{
${ }^{2}$ Cheguei a distribuir 70 (setenta) questionários, mas só obtive o retorno de 47.
} 
fomentar a: "oferta emergencial de cursos de licenciaturas e de cursos ou programas especiais dirigidos aos docentes em exercício há pelo menos três anos na rede pública de Educação Básica [...]."3

A CAPES informa, em seu relatório de gestão (2009-2013), que em quatro anos o PARFOR ofertou 244.065 mil vagas $(70,09 \%$ em cursos de primeira licenciatura, $26,59 \%$ em cursos de segunda licenciatura e 3,32\% de formação pedagógica). O curso com o maior número de vagas solicitadas foi o de Pedagogia que em 2013 foi responsável por 15,46\% do total de vagas, seguido pelo de Artes $(9,97 \%)$. Já os menos solicitados foram os de Sociologia $(2,63 \%)$, Filosofia $(2,62 \%)$ e Espanhol (2,61\%).

Das vagas ofertadas pelo PARFOR quase metade atenderam a Região Norte $(48,86 \%)$ e mais de um terço a região Nordeste $(38,18 \%)$. O estado que lidera o quantitativo de matrículas é o Pará com 29,24\%, provavelmente por apresentar $33,13 \%$ de professores exercendo funções docentes sem formação superior. $\mathrm{O}$ valor desembolsado para a manutenção do programa é bastante expressivo, só entre os anos de 2009 a 2013 foram gastos com o PARFOR mais de meio bilhão de reais (precisamente $R \$ 529.111 .171,35)$, algo que pode ser constatado na tabela a seguir:

Tabela 1. Financiamento de turmas especiais presenciais especiais do PARFOR - 2009 a 2013

\begin{tabular}{l|c}
\hline ANO & Totais por ano $(\mathrm{R} \$)$ \\
\hline 2009 & $12.394 .341,09$ \\
\hline 2010 & $70.914 .408,33$ \\
\hline 2011 & $110.987 .220,82$ \\
\hline 2012 & $162.895 .436,02$ \\
\hline 2013 & $171.919 .765,09$ \\
\hline
\end{tabular}

${ }^{3}$ O PARFOR deve, especificamente, fomentar a oferta de cursos de: a) licenciatura, cujo público alvo são docentes ou tradutores intérpretes de Libras que estejam atuando na rede pública da Educação Básica e que não tenham formação superior (essa oferta também se destina àqueles que tendo essa formação se interessem por cursar uma nova licenciatura na etapa/disciplina em que atua em sala de aula); b) segunda licenciatura, voltada para professores licenciados e que estejam exercendo o magistério há pelo menos três anos na rede pública de Educação Básica, no entanto, atuando em área distinta da sua formação inicial (Essa oferta abrange também profissionais licenciados que atuam como tradutores intérpretes de Libras na rede pública de Educação Básica; e c) formação pedagógica, indicada para professores ou tradutores intérpretes de Libras graduados não licenciados e que se encontram no exercício do magistério na rede pública de Educação Básica (CAPES, 2013). 


\section{\begin{tabular}{l|l}
\hline Total & $529.111 .171,35$ \\
\hline
\end{tabular} \\ Fonte: CAPES (Relatório de Gestão 2009-2013)}

Como se verifica na Tabela 1 , no primeiro ano de implantação do Programa foi aplicado um pequeno valor se comparado aos anos posteriores. Certamente, o montante de mais de meio bilhão de reais gastos até o momento não é um valor nada desprezível.

$\mathrm{O}$ ingresso nos cursos é muito simples. Primeiramente o candidato precisa cadastrar-se no EDUCACENSO na função Docente ou Tradutor Intérprete de Libras na rede pública de Educação Básica. Em seguida basta realizar o cadastro na Plataforma Freire e fazer uma pré-inscrição e aguardar até que esta seja deferida pela Secretaria de Educação a qual o docente estiver vinculado e aguardar o resultado da seleção feito por uma IES (Instituição de Educação Superior) credenciada junto ao PARFOR. Apesar de muitas matrículas validadas não serem aceitas, desde 2011 o percentual de matriculados vem aumentando. Em 2011 foram 21,76\%, no ano seguinte aumentou para 24,69\% e em 2013 alcançou $32,10 \%$ de matriculados. Assim, na mesma medida em que os gastos com o Programa aumentaram ano a ano, verifica-se, também, o crescimento percentual no atendimento das demandas.

O PARFOR é um Programa que tem atendido uma quantidade cada vez maior de docentes e, de algum modo, produzido determinados resultados. Tratase, também, de uma política pública de formação de professores bastante consolidada no cenário da educação pública brasileira.

\section{Sobre a semiformação}

A semiformação 'não pode ser explicada a partir de si mesma, porque constitui resultado de um processo de dominação sistemática por mecanismos das relações político-econômicas dominantes' (SchmiedKowarzik, 1983, p. 114). Não basta permanecer no 'plano' da sujeição; é preciso avançar à própria produção desse "plano", conforme uma "teoria mais ampla". Cabe responder à pergunta: "Como os homens se sujeitam a si próprios, impondo a si o imperativo categórico: 'Sujeita-te àquilo que existe!?'” (Adorno, 1973, p. 67). A sujeição efetivamente vale como determinação "objetiva" no "plano" do já "objetivado" pelo verdadeiro "sujeito", revelado "para além" da sociedade já constituída, como aquele "sujeito limite da reificação", porque ele "produz reificação" e "se subordina voluntariamente a ela". (MAAR, 2003, p. 468). 
Na "Dialética do esclarecimento" Horkheimer e Adorno (1985), analisando especificamente a questão da indústria cultural, percebem o forte poder de manipulação que esse tipo de indústria exerce sobre a consciência dos indivíduos, o que abre caminho para acentuar crise nos mecanismos de formação (bildung), indicando, assim, o indício de uma crise mais ampla no interior dos processos formativos.

Cumpre frisar que o termo semiformação aparece pela primeira vez na "Dialética do esclarecimento" de Horkheimer e Adorno (1985), citado em "Elementos do anti-semitismo". Nessa mesma obra, Horkheimer e Adorno criticam o processo de produção cultural na sociedade capitalista, encargo assumido pela indústria cultural. Edifica-se, assim, o instrumento, por excelência, encarregado de fabricar as mercadorias culturais. Os meios de comunicação de massa, imbuídos em disseminar esse tipo especial de mercadoria, propagam um tipo de cultura cujos interesses estão distantes dos propósitos de uma cultura genuinamente popular.

Esse processo de fabricação da cultura passou a ser realizado por empresas e instituições que criam produtos e entretenimentos padronizados para o grande público. Segundo análise efetuada por Duarte (2003, p. 9) esse tipo de cultura representa "[...] um campo de exploração econômica, administrado de cima para baixo e voltado apenas para os objetos supramencionados que produzem lucros $e$ garantem adesão ao sistema capitalista por parte do público". Distante, portanto, de representar um instrumento de formação cultural, a indústria cultural contribui para o contrário: a deformação da cultura e da consciência. Colabora, então para difundir o ethos da sociedade capitalista em suas manifestações de ser, pensar, agir, viver, sob a batuta de determinadas crenças que ajudam na reprodução do metabolismo social desigual e excludente, revigorando os valores da sociedade do consumo e seu caráter fetichista.

Concomitante a reprodução ampliada da indústria cultural, observou-se o crescimento acelerado da semiformação e do homem semiformado. Ao mesmo tempo em que a indústria cultural passava a ocupar espaço privilegiado na formação das pessoas, verifica-se a regressão da consciência, da autonomia, do 
pensamento livre. A reprodução metabólica do capital possuía agora um verdadeiro mastodonte a seu dispor. A formação do pensamento único, heterônomo tinha agora um forte aliado, pois a indústria cultural expandia, extraordinariamente, determinados valores, preceitos, visão de mundo e os padrões de conduta capitalista na interioridade do indivíduo massificado. Esse, tendencialmente cada vez mais passivo, dominado e resignado diante do colossal poder a qual teria que se submeter. Naufraga, assim, os propósitos iniciais da cultural (a autêntica formação humana) ao mesmo tempo em que se fortalece a semiformação, promotora de uma subjetividade reificada e alienada no interior das práticas sociais.

Para ele [o homem semiformado] todas as palavras se convertem num sistema alucinatório, na tentativa de tomar posse pelo espírito de tudo aquilo que sua experiência não alcança, de dar arbitrariamente um sentido ao mundo que torna o homem sem sentido, mas ao mesmo tempo se transformam também na tentativa de difamar o espírito e a experiência de que está excluído, e de imputar-lhes a culpa, que, na verdade, é da sociedade que o exclui do espírito e da experiência. Uma semicultura [ou semiformação] que por oposição à (a) simples incultura [ou ausência de formação] hipostasia saber limitado como verdade, não pode mais suportar a ruptura entre o interior e o exterior, o destino individual $e$ a lei social, a manifestação e a essência. Essa dor encerra, é claro, um elemento de verdade em comparação com a simples aceitação da realidade dada [...]. Contudo a semicultura, em seu modo, recorre estereotipadamente à fórmula que lhe convém melhor em cada caso, ora para justificar a desgraça, ora para profetizar a catástrofe disfarçada, às vezes, de regeneração. [...] Os sistemas obscuros realizam hoje o que o mito do diabo da religião oficial realizava na Idade Média: a atribuição arbitrária de um sentido à realidade exterior. [...] a real emancipação dos homens não ocorreu ao mesmo tempo que o esclarecimento do espírito [...] quanto mais a realidade social se afasta da consciência cultivada, tanto mais esta se via submetida a um processo de reificação. A cultura converteu-se totalmente numa mercadoria. O pensamento perde o fôlego e limita-se à apreensão do fatual isolado [...] o pensamento reduzido ao saber é neutralizado e mobilizado para a simples qualificação nos mercados de trabalho específicos e para aumentar o valor mercantil das pessoas. Assim naufraga a auto-reflexão (autorreflexão) do espírito que se opõe à paranoia. Finalmente, sob as condições do capitalismo tardio, a semicultura converteu-se no espírito objetivo (HORKHEIMER e ADORNO, 1985, p. 182-184).

Horkheimer e Adorno (1985) responsabilizam a constituição da sociedade capitalista pelo processo (de)formativo produzido pela indústria cultural, uma vez que essa promove a aceitação da realidade dada, distanciando os homens do esclarecimento e também da emancipação. A denúncia de Horkheimer e Adorno 
de que na sociedade administrada pelo capital a cultura converteu-se totalmente numa mercadoria permanece atual, uma vez que o predomínio da indústria cultural na formação das pessoas ocupa espaço bastante privilegiado.

Vale refletir que, ao contrário do que se poderia supor, o alcance de um diploma de curso superior não significa libertação dos preceitos mercantis incutidos na produção cultural fetichizada. Sobretudo, o homem semiformado, mesmo que tenha o valor mercantil de sua personalidade elevada, em razão de possuir um diploma, ainda não reúne forças para realmente se emancipar, torna-se "espírito livre", independente dos "diretores de consciência", campo fértil para a manutenção e reprodução do preconceito, do pensar por estereótipos - formas do pensar alheias a todo ordenamento social que busque a realização do princípio básico da democracia, qual seja, o da autonomia do sujeito.

Nesse sentido, testemunhamos a existência daquilo que Adorno (1996) entendeu como semiformação (Halbbildung) que é a determinação social da formação na sociedade contemporânea capitalista que colabora para difamar o espírito e a experiência de quem está excluído, estorvando processos e projetos de cunho emancipatório, dicotomizando a realidade social do tipo de consciência que se cultiva sobre ela. Nesse sentido, a semiformação faz parte do âmbito da reprodução da vida sob o monopólio da "cultura de massas", cuja indústria cultural oferece inestimável contribuição (de)formativa e agindo no caminho da estultificação das consciências. Vivenciamos um processo de intensificação da semiformação cujos propósitos ocultam uma vida danificada, reduzida em sentido e significado e cada vez mais individualista e competitiva. Trata-se da instituição de um sistema alucinatório que busca, sem conseguir sucesso, encontrar algum sentido à vida e cujo espírito procura localizar consolo e refúgio no acesso aos produtos culturais oferecidos e que ajudam a suportar a cisão entre o interior e o exterior, o destino individual e a lei social, a manifestação e a essência.

Em tempos de semiformação generalizada percebemos a precarização da formação cultural. Os ávidos consumidores, distantes de se tornarem sujeitos autônomos, fortalecem os laços heterônomos da existência e do enfraquecimento de uma relativa autonomia. A ideia de homem, tal como concebida pelo 
Iluminismo, é anulada. Se em algum momento da história humana houve o interesse do bem estar coletivo, esse definha diante da obstinada perseguição pela felicidade individual, fama, dinheiro, beleza e glória. Talvez por isso o interesse em ficar rico, ser uma celebridade (ou sub), consumir cada vez mais, ser um "espetáculo" ganha cada vez mais espaço nos sonhos das pessoas ${ }^{4}$. Ao mesmo tempo, o egoísmo, a competição insaciável, o individualismo exacerbado e o consumismo compulsivo se fortalecem.

Essa semiformação, ao contrário da autêntica formação cultural (bildung), reforça a alienação e a compreensão ideológica, preconceituosa e estereotipada do mundo e pouco contribuem para uma interpretação crítica da realidade concreta, para a autonomia e a emancipação. Nesse sentido, é preciso educar pessoas com essa personalidade. E trata-se de um processo que se desenvolve em todos os níveis da educação formal, o que requer uma atenção cuidadosa com a formação de profissionais que irão atuar na educação das novas gerações. Nesse caso, os futuros educadores deverão, também, ser semiformados. .

É a partir desse aporte teórico que analisarei os dados coletados, emergidos da tensão presente nas relações sociais que engendram e ensejam a produção de uma falsa consciência, que hipostasia as relações concretas de existência e garantem a reprodução do vigente regime de acumulação. Tendo em vista essas considerações surgem algumas indagações: a) até que ponto a forma como o PARFOR se desenvolve possibilita a articulação entre teoria e prática em todo o percurso formativo?; b) Em que medida o PARFOR promove a garantia do domínio de conhecimentos científicos e didáticos e a indissociabilidade entre ensino, pesquisa e extensão? Essas indagações são necessárias por constituírem "os princípios que devem orientar as IES no planejamento pedagógico do PARFOR (CAPES, 2013).

\footnotetext{
${ }^{4} \mathrm{Na}$ "Sociedade do espetáculo" Debord (1997) fomenta uma discussão bastante peculiar sobre esse processo, pois, de um modo geral, se dissemina, especialmente pela mídia, o estereótipo de um protótipo, despertado por astros e celebridades, de um tipo de padrão e formação cultural que tende a valorizar quem é "famoso". Isso justifica a tentativa de pessoas anônimas de querer ser o que aquelas pessoas aparentam ser. Passa despercebido, a quem também deseja ser um espetáculo, de que as celebridades cultuadas nada mais são do que subprodutos artificiais cujo propósito é divulgar e vender mercadorias.
} 


\section{A expansão do ensino superior ou a propagação da semiformaçao?}

\section{IV.I. Aspectos comuns}

Os cursistas, de um modo geral, têm uma impressão inicial muito favorável à implementação do PARFOR. Afirmam que percebem o programa como uma grande oportunidade para complementarem os estudos, se qualificarem e poderem melhorar o desempenho da docência. Todavia, ao longo do curso, notaram algumas dificuldades relacionadas à "dura realidade" (trecho da fala presente nas respostas de muitos discentes), pois precisavam conciliar estudos e trabalho durante os anos de vínculo à instituição.

Além conciliarem tantas atividades é comum, nas localidades distantes do centro urbano, que docentes assumam disciplinas diferentes de sua formação inicial. Dos entrevistados, 39 afirmaram que passam por essa situação e destacaram as dificuldades que sentiam: "Ainda que eu entenda um pouco do assunto, não me sinto à vontade. Sei que para lecionar de verdade é preciso de muito mais entendimento do assunto" (Cursista de Marabá).

Os docentes ponderam que possuem poucas oportunidades para a formação continuada. "Raramente tive a oportunidade de participar de algum curso que me ajudasse a melhorar a minha prática" (informa o cursista de Santarém). Registro aqui que dos 47 (quarenta e sete) discentes que preencheram o questionário apenas 3 (três) residiam nos municípios onde frequentavam as aulas. Alguns enfrentavam até um dia inteiro de viagem para estarem presentes no curso e frisaram a importância de estarem ali. Assim, como relatou um dos entrevistados: "O PARFOR representa para mim essa possibilidade de estudar, de continuar estudando, algo que era improvável em outro momento" (Cursista Moju).

No começo do curso muitos não perceberam que ficariam praticamente 4 (quatro) anos sem férias, uma vez que os cursos geralmente funcionam durante o recesso escolar ou durantes as férias anuais. Mas estavam dispostos a não evadirem, pois dificilmente teriam a oportunidade de frequentar um curso de nível superior em uma universidade pública outra vez. Algo destacado pelo cursista de Belterra: "Estudar em uma universidade pública é um sonho. E mesmo com todas 
as dificuldades irei ficar até o fim. Nem esperava mais essa oportunidade. Agora que apareceu, não vou abandonar'.

Segundo os partícipes da pesquisa, um dos fatores que atrapalham os estudos é a distância da família. Dessa forma, relata um dos cursistas: "Talvez esse seja o maior desafio: ficar longe da família. Eles entendem minha situação. Não é fácil. Isso dificulta a concentração, mas espero que valha a pena todo o esforço" (Cursista de Abaetetuba). Sob esse aspecto identifiquei que dos 47 (quarenta e sete) discentes consultados, apenas dois não possuíam relação estável e apenas 7 (sete) ainda não possuíam filhos.

A primeira graduação de 40 (quarenta) participantes da pesquisa empírica havia sido realizada em instituições privadas. Desses, 28 (vinte e oito) haviam feito a licenciatura na modalidade a distância. Identifiquei que 4 (quatro) discentes chegaram a começar estudos de graduação em instituições privadas, porém, não conseguiram terminar e 3 (três) não nunca tinham iniciado os referidos estudos. Para esses o PARFOR representava, portanto, a primeira oportunidade de frequentar um curso superior, "Eu leciono há cinco anos sem ter qualificação para isso. Então o PARFOR é a oportunidade que tanto esperava. Ainda que eu enfrente dificuldades, vou até o fim" (Cursista de Rio Maria).

Dentre os que haviam cursado e concluído alguma graduação, todos destacam as lacunas da formação inicial. Entendem que essa não atendeu as expectativas objetivadas, o que, por sua vez, exige a permanente atualização dos estudos, algo de difícil acesso nas localidades onde moram. Esses se mostram, de algum modo, insatisfeitos com o tipo de formação inicial recebida e esperam uma melhor qualidade na nova graduação. Porém, destacam que os gestores de seus municípios criam uma série de dificuldades para que eles possam conciliar o exercício da docência com a frequência dos cursos.

Não há apoio do governo municipal. Não recebemos nenhum tipo de incentivo. Eles sabem que não teremos recesso por conta do curso. Porém, eles não admitem que demoremos a retornar para assumirmos as turmas. Cobram muito e oferecem pouco (Cursista Santarém).

Estou aqui no PARFOR muito mais por minha força de vontade do que pelo apoio e incentivo do prefeito. Eles colocam todas as dificuldades possíveis para que não venhamos estudar, pois isso atrasa o inicio do 
ano letivo na escola [...]. Atrasa porque quase sempre coincide o término das aulas do PARFOR com o começo do ano letivo nas escolas. A diretora sabe que estou estudando e mesmo assim me dá falta (Cursista Moju)

Isso ocorre, pois, geralmente o período letivo dos cursos ofertados pelo PARFOR coincide com o começo das aulas nos municípios onde trabalham. Os gestores desconsideram este fato e cobram o retorno dos docentes que, em alguns casos, acabam pagando para alguém os substituírem. Informam, também, que jamais receberam auxílio financeiro de nenhuma esfera do poder público para custear determinadas despesas provenientes do curso (como aluguel, transporte, alimentação), necessárias para deslocamento de suas localidades de origem até as cidades onde são ofertados os cursos do PARFOR. Nesse caso, se quiserem permanecer estudando, terão que arcar com os custos.

Informam a imensa dificuldade em ler os textos trabalhados pelo professor em sala de aula (geralmente apostilas produzidas por algum professor vinculado a IES, promotora do curso). Isso ocorre muito mais em razão do tempo disponível para a leitura (pois as aulas, em regime modular, ocorre em dois turnos cada um com duração de cinco horas-aulas por dia, inclusive durante os sábados) e também pela dificuldade em interpretar os textos que os professores utilizam. Segundo o relato dos cursistas:

Vou ser sincero: leio pouco durante as aulas. E não é por preguiça. É por pura falta de tempo. O ritmo das aulas é puxado. Aula de manhã e de tarde, inclusive aos sábados. No fim de semana, temos que nos ocupar com alguns afazeres domésticos, o que dificulta ainda mais o tempo pra leitura (Cursista de Belterra).

Confesso que tenho dificuldades com os textos da apostila. Eu sou assim, preciso de mais tempo para ler e entender os textos. Só que o tempo não permite isso. Então é o jeito ir lendo do jeito que dá. E é claro que isso é um obstáculo para minha formação (Cursista Castanhal).

Por um lado, o tempo para leitura dos textos é pequeno e por outro lado eu ainda sinto uma certa dificuldade pra entender, pois são coisas complexas, coisas novas que eu anda não tinha estudado direito. (Cursista Marabá)

Aliado a isso, os docentes destacam a dificuldade em acessar livros para consultas e leituras. Geralmente, os exemplares indicados pelos professores não constam no acervo da biblioteca. Enfatizo também que, exceto o campus de Belém 
e o polo de Moju, os polos de Marabá e Santarém da UEPA não possuem turmas regulares de Pedagogia, o que justifica essa informação dada pelos discentes.

Mesmo entre os discentes de Belém e Moju, foi relatado que dificilmente há disponível na biblioteca os exemplares indicados pelos docentes que ministram cursos no PARFOR. É importante considerar que o tempo dedicado à leitura é curto, conforme informações coletadas:

\section{TABELA 2. Sobre o tempo destinado a leitura durante o período do curso}

\begin{tabular}{l|l}
\hline Horas por dia & Quantidade de docentes \\
\hline Pelo menos uma hora & 11 \\
\hline Até duas horas & 28 \\
\hline Até três horas & 5 \\
\hline Até quatro horas & 2 \\
\hline Até cinco ou mais horas & 1 \\
\multicolumn{2}{l}{ Fonte: Farias Jr. Pesquisa de campo. }
\end{tabular}

Os 47 (quarenta e sete) discentes pesquisados relatam que durante a vigência do curso não tiveram a oportunidade de lerem na íntegra nenhum livro, seja porque os professores já trazem gratuitamente os textos apostilados, seja pela falta de tempo durante o curso, uma vez que tão logo se encerre o período letivo eles precisam retornar imediatamente para seus municípios e retomarem suas atividades de docência. Essa política de oferecer o "material didático" ao aluno, ainda que de algum modo necessária devido ao fato do difícil acesso a outros tipos de leitura, acaba substituindo a consulta a livros de maior densidade $e$ aprofundamento teórico.

Por outro lado, informaram que durante a realização da outra graduação não recordavam de terem lido muitas obras na sua totalidade, mas, principalmente, partes ou capítulos de livros:

Basicamente durante minha primeira graduação não recordo de ter lido alguma obra inteira. Agora li muitos textos (artigos, né?) que o professor trazia para a aula (Cursista de Rio Maria).

Realmente eu precisava ter lido mais. Foi uma falha na minha formação, pois nem graduação anterior e nem nessa aqui na UEPA ainda não li nenhuma obra por inteiro (Cursista Santarém).

Eu não tenho certeza se no outro curso eu li um livro inteiro. Mas nesse, com certeza não li. Na graduação isso ocorreu mais por causa da falta de 
condições, pois o curso era a distância e tal... Mas agora falta tempo mesmo. Mesmo quando voltamos para nossos municípios a gente tem que conciliar trabalho, familia e sobra pouco tempo pra estudo mesmo, o que dificulta muito isso (Cursista de Abaetetuba).

Situação delicada, tendo em vista que a leitura é elemento basilar no processo formativo de qualquer pessoa. Então, de algum modo, a política de oferta do "material didático", quase sempre reunindo textos resumidos e de baixa densidade teórica, deveria ser repensada na formação dos discentes.

Algo observado por meio das informações oriundas da aplicação do questionário é que nenhum informante havia publicado durante a realização do curso algum artigo completo em eventos de natureza acadêmico-científica. Apenas dois alunos do polo Belém já publicaram um resumo (embora não recordassem) em um dos eventos da UEPA. Todavia nenhum dos informantes havia participado de projetos de pesquisa e extensão, muitos menos de grupos de pesquisa cadastrados no CNPq e certificados pela UEPA. Informam, ainda que mesmo para a produção do Trabalho de Conclusão de Curso, que deveria representar um trabalho de iniciação científica, tiveram pouco contato com o professor/orientador, sendo que a maior parte do contato com o orientador se deu "a distância", por meio de redes sociais ou via e-mail ou telefonemas.

Cabe aqui o reporte à invenção "universidade moderna", cuja referência é o modelo humboldtiano, caracterizado pela transformação das funções da universidade, lastreada na disseminação do ensino, na produção do conhecimento via pesquisa científica e propagação da extensão. Na presente configuração da sociedade capitalista, esse modelo, no tocante a sua expansão nos países de economia emergente, vai sendo substituído por outro arquétipo de universidade: o modelo neoprofissional onde se percebe a despreocupação com a pesquisa e a extensão (considerados dispendiosos) e a concentração das atividades acadêmicas no ensino. ${ }^{5}$ Se faltam aos discentes o acesso à pesquisa e à extensão, isso não

\footnotetext{
${ }^{5}$ A emergência desse modelo de universidade se desenvolve segundo Sguissardi (2005, p. 212) especialmente em países centrais e periféricos, "onde as políticas de educação superior caracterizam-se pela redução permanente do financiamento estatal da educação superior pública, pelo estancamento de sua expansão, pelo congelamento salarial do staff universitário, pela perda de direitos trabalhistas, pela flexibilização dos contratos de trabalho, diferenciação institucional, diversificação de fontes de financiamento, e pelo implemento das universidades de ensino ou neoprofissionais em detrimento das universidades de pesquisa". (grifos do autor)
} 
configura um indício de uma "meia" formação? Essa formação "parcial", onde os requisitos mínimos estão ausentes, por mais que represente algum tipo de formação, acaba por constituir um obstáculo à formação desejada por alguém que busca na Educação Superior, algo mais do que a mera certificação de suas "habilidades" e "competências" requeridas para a sua atuação profissional.

\section{II. O PARFOR e a propagação da semiformação}

A universidade é uma instituição de uma "sociedade administrada" (ADORNO; HORKHEIMER, 1985). Dessa forma, interagem com a ideologia (liberal) que serve de fulcro para a reprodução das relações sociais capitalistas. De um modo geral, a Educação, Básica ou Superior, estrutura-se como ferramenta da indústria cultural e reprodutora da semiformação, ao suprimir subjetividades e conformando-as ao sistema de produção capitalista. A expansão do modelo de universidade neoprofissional, baseado apenas no ensino, desvinculado da pesquisa e da extensão (marcas do modelo expansionista da Educação Superior brasileira e também internacional - nas últimas duas décadas), oferece, em especial nos cursos de licenciatura (geralmente frequentado por pessoas oriundas de setores populares), uma formação pela "metade".

No que concerne à formação, os docentes expõem que o PARFOR representou uma excelente oportunidade de se formarem por uma instituição pública. Ressaltam que já não nutriam muitas expectativas em relação a esse almejado sonho. Nas palavras do cursistas de Belém, Moju e Marabá.

Foi um curso muito bom. Posso dizer que muito e ajudou a entender melhor o que eu faço. Mas sempre fica aquela sensação de que poderia ter sido melhor. Me refiro a alguns educadores que vem pra cá e veem a gente como coitadinhos, que não conseguem aprender e tal. Poderiam ter exigido mais da gente. Mas também tem alunos que não se esforçaram muito durante o curso. Mas não posso esquecer que as condições não são as melhores. A maioria mora no interior e têm dificuldades no acesso a livros e outros materiais. O material didático que recebemos é muito simples, sabe... E ficamos muito preso nele. (Cursista de Belém)

Eu tenho um curso de matemática, mas trabalho nas séries iniciais. Meu primeiro curso foi feito todo a distância. Então senti muita dificuldade em ensinar matemática. Aí me pediram pra lecionar as crianças do ensino fundamental. Por isso, entendo que o curso de pedagogia foi muito bom. [...] Agora não foi o ideal. Saio do curso sentindo que faltou algo. Ainda 
não me sinto seguro pra trabalhar com crianças, ainda mais com essas que tem que ler e escrever. Nesse aspecto o curso deixou a desejar. (Cursista de Moju)

Imaginei que a nossa formação seria melhor. Criei muita expectativa sobre o curso. E não saio muito satisfeito. Os anos finais deixaram muito a desejar. Não sentia muito esforço dos professores e isso fez com que a turma não se empenhasse muito. Poderia ter sido melhor (Cursista de Marabá)

Parece que a sensação de que "poderia ter sido melhor" é bastante presente na fala dos discentes. De modo geral, eles atribuem isso à : a) estrutura modular/intervalar dos cursos; b) rapidez com que as aulas ocorrem; c) falta de disponibilidade de outros materiais para leituras; d) falta de qualificação ou experiência de alguns docentes.

Primeiramente, observa-se que, com muita frequência, os alunos questionam a modalidade de oferta modular-intervalar (forma de oferta de ensino superior quase que absoluta pela UEPA nos campus do interior do Estado do Pará), Já a "rapidez" das aulas, refere-se à intensidade com que se dá o desenvolvimento de cada disciplina (em dois turnos, todos os dias, exceto aos domingos), algo observado como aspecto negativo apontado pelos alunos. Por outro lado, ainda que admitam a falta de tempo para realizar outras leituras, os discentes indicam que necessitam ter acesso a mais obras além da apostila utilizada pelos professores, em razão da dificuldade de terem acesso a outros materiais em seus municípios de origem.

Porém, a principal queixa dos alunos é referente à "falta de qualificação dos docentes". Embora a preferência para a lotação de docentes obedeça prioritariamente os efetivos e só depois os substitutos ou -estudantes de mestrado $e$ doutorado ou eventuais colaboradores externos à instituição, o que se verifica, em razão, sobretudo, da necessidade de atender a grande oferta de cursos nos municípios, é que a maioria dos docentes que atuaram no PARFOR-UEPA não pertenciam ao quadro efetivo da UEPA. Além disso, muitos docentes, por conta da necessidade, eram lotados em disciplinas em que possuíam pouca ou nenhuma experiência, algo que os discentes cursistas do PARFOR/UEPA de algum modo identificaram. 
Em relação ao ensino, pesquisa e extensão os cursistas apontam algumas questões a considerar: Primeiramente demonstram certa decepção em relação à articulação ensino-pesquisa-extensão, pois, ainda que muito propalada pelas falas dos docentes-formadores, terminaram o curso sem entender como se daria essa articulação. Entendem que houve ensino, mesmo que distante do ideal, porém, não souberam dissecar com propriedade as questões referentes ao desenvolvimento de atividades de pesquisa e extensão, problema, aliás, enfrentado por todas as universidades públicas brasileiras, em razão dos sucessivos cortes governamentais, seja na esfera Federal ou na Estadual, na manutenção da Educação Superior, com prejuízos às s atividades de pesquisa e extensão. Soma-se a isso, o fato de que vários docentes lotados em muitos cursos do PARFOR, além de não terem vínculos efetivos com a instituição (o que os desobriga de realizarem pesquisa e extensão para a universidade), serem lotados em disciplinas em que não tinham muita experiência. Algo latente, por exemplo, durante a orientação do TCC, pois:

\begin{abstract}
A orientação de TCC não foi legal, pois o professor vinha aqui pra orientar 4 trabalhos, além do meu e era tudo muito rápido, percebia que ele não lia com muita atenção e fazia poucas correções. Mas o processo de orientação, que não foi culpa do professor, não foi muito legal. Foi basicamente uma orientação a distância, por e-mails... Senti que poderia ter produzido um trabalho bem melhor, mas faltou algo, sabe (Discente de Rio Maria).
\end{abstract}

Quase que não consigo terminar o curso por causa do TCC. Vou ser sincero. Podia ter rendido mais, mas não deu. Não vou negar que faltou algo mais de minha parte. Mas também senti falta de uma orientação maior. Eu, como outros colegas, tivemos pouco isso. E terminamos o TCC na marra. Senti que não estava um bom trabalho. Isso eu reconheço. Mas o importante foi que a banca deu 10. Eu não vou reclamar da nota, né? Ainda mais porque outros colegas, que nem fizeram um trabalho pior que o meu também tiraram nota igual a minha (Discente de Belterra).

Considerando as informações dos fragmentos das falas dos discentes entrevistados, observo que a produção do TCC, por se tratar de um trabalho de natureza científica, não ocorreu de forma satisfatória, pelo menos na perspectiva apontada pelos discentes. Na realidade as questões apresentadas pelos depoentes indicam um problema que não é comum apenas ao curso do PARFOR, visto que se trata de uma questão que envolve praticamente boa parte do ensino superior. 
No que concerne à extensão o contato dos discentes com essa momento do tripé acadêmico é ainda mais remoto. Dentre os alunos partícipes desse estudo nenhum havia se envolvido com algum tipo de extensão universitária, embora "[...] eu acharia importante ter tido a oportunidade de participar disso. Mas saio da universidade sem saber direito o que é isso de fato" (Cursista de Moju).

Um elemento bastante presente na coleta dos depoimentos que integram a pesquisa aqui realizada diz respeito à percepção da qualidade dos cursos. Os discentes entrevistados a todo o momento ressaltam os aspectos positivos de terem terminado um curso superior em uma universidade pública. Porém, destacam muitos aspectos que servem de estorvo a qualidade do curso oferecido. Destacam a necessidade de enviarem docentes mais experientes e, preferencialmente, efetivos para ministrar as disciplinas. Apontam a importância da disposição de farto material bibliográfico. Indicam ainda que é preciso fazer a pesquisa e a extensão universitária chegar até os alunos do PARFOR, além de questionarem a modalidade intensiva dos cursos que ao longo do tempo se tornam cansativos $e$, por sua vez, menos produtivos. Entendo que as questões apontadas pelos discentes necessitam ser alvo de profunda reflexão por parte dos agentes públicos responsáveis pela implementação do PARFOR. Trata-se de uma política pública que pode ser potencializada e ir além da mera quantificação de professores.

$\mathrm{O}$ paradoxo que envolve o dialético movimento relacionado à questão da quantidade da certificação com a qualidade da formação não é algo facilmente traduzido, principalmente, quando consideramos que muitos fatores sociais, políticos e econômicos estão em jogo, em especial aqueles fatores ocultos na política de formação de professores no Brasil. A quem interessa a quantidade da certificação e a quem interessa a qualidade da formação? Captar a essência desse movimento exige rigor teórico para descortinar a verdadeira distância entre "intenção e gesto".

\section{Considerações provisórias}

De acordo com Pucci (2007), para Adorno (1996) a semiformação representa a forma dominante da consciência atual. Adorno (1996) havia 
percebido que a tradicional formação cultural havia se convertido na "onipresença do espírito alienado". Dessa forma Pucci (2007), embasado em Adorno, observa que se esse é o processo histórico e regressivo da ideia de formação cultural, é esse processo que deve ser observado em sua negatividade e com rigor, e não o seu avesso (PUCCI, 2007).

Adorno (1996), opondo-se à "onipresença do espírito alienado", chega a sugerir alguns elementos norteadores de uma educação crítica, oposto da artificial modelagem de pessoas. E, contrário a uma educação engajada na mera transmissão de conhecimentos, Adorno (2003) propõe uma formação que seja capaz de promover a formação de uma consciência verdadeira.

Assim, se por um lado o objetivo do Plano Nacional de Formação de Professores da Educação Básica eram o de equalizar as oportunidades de formação inicial e continuada dos profissionais do magistério, por outro, a partir dos dados levantados no estudo aqui delimitado, muitos fatores concorrem para que esse escopo do referido programa seja realmente efetivado. Analisando os dados empíricos coletados para fins de realização dessa pesquisa entendo que, para além do discurso da qualificação e do compromisso com a qualidade da formação, o que em grande parte se materializa é a certificação em massas dos docentes. Nesse caso, não ocorre uma formação autêntica (bildung), mas a semiformação (Halbbildung). Aliás, a Halbbildung é o aspecto dominante em nossa sociedade, marcada pelo forte poder que alcançou a indústria cultural.

Adorno (1996), preocupado em elaborar uma crítica à teoria positiva da formação cultural, esboça os limites da formação numa sociedade capitalista, apontando as evidentes deficiências formativas, procura desenvolver reflexões que permitam detectar criticamente a realidade em que se transformou a formação cultural. Com isso, demarca a contraposição entre formação cultural $e$ semiformação. Adverte o teórico frankfurtiano que a semiformação não significa a metade do caminho em direção àquela, e sim um obstáculo de difícil transposição. Então, de um modo geral, considerando os diversos fatores que colaboram para isso, o PARFOR, enquanto política de formação inicial e continuada de professores, encontra obstáculos para se constituir enquanto política pública que 
ofereça uma formação autêntica a seus discentes, algo que não é exclusivo do PARFOR.

Os fatores apontados pelos partícipes do estudo aqui realizado, não reduzindo a importância do PARFOR na trajetória desses alunos, indicam que o programa aqui investigado enfrenta desafios que obstaculizam a consecução dos objetivos elementares do mesmo, em especial no cenário amazônico. Parece que a efetivação do programa se aproxima de uma reflexão de Adorno quando este observa que o entendido e experimentado medianamente - semi-entendido e semiexperimentado - não representa o grau elementar da formação, e sim seu inimigo mortal (ADORNO, 1996).

Analisando as questões apontadas durante as duas fases da pesquisa empírica, verifico que prevalece na formação oferecida pelo PARFOR uma tendência ao semi-entendido e semi-experimentado, sobretudo quando observamos as dificuldades que os discentes possuem em articular ensino, pesquisa e extensão. Dificuldade que também é evidenciada durante a orientação do TCC, por exemplo.

Reporto-me, aqui, a uma antiga indagação kantiana: "Vivemos nós numa época esclarecida?" A resposta de Kant (1990), certamente contrária àqueles que advogam vivermos na sociedade do "conhecimento", é: não, uma vez que Kant acreditava, já na sua época, que ainda faltava muito para que os homens pudessem fazer uso adequado de seu entendimento e agir sem a tutela de outrem, ainda que percebessem sinais de que os obstáculos ao esclarecimento estavam sendo diminuídos. Adorno, leitor de Kant, sempre se mostrou preocupado com essas questões. A defesa de uma formação cultural que libertasse o homem da tutela alheia e o fizesse agir com autonomia, era uma das premissas centrais do pensamento adorniano.

Provavelmente se Adorno estivesse vivenciando o atual momento de expansão da Educação Superior, ao observar o processo de mercantilização acentuada da mesma, talvez considerasse que essa cumprisse a tarefa de formar indivíduos para o mercado de trabalho, esses ávidos por ganhar a "independência" financeira, sem, no entanto, estarem preparados a vivenciarem outras experiências 
formativas, pois "O defeito mais grave com que nos defrontamos atualmente consiste em que os homens não são mais aptos à experiência, mas interpõem entre si mesmos aquilo a ser experimentado, aquela camada estereotipada a qual é preciso se opor" (ADORNO, 2003, p.148-149).

A questão da semiformação, por sua vez não é algo peculiar do PARFOR, muito menos relativo apenas à educação, uma vez que Adorno (1996) já havia percebido que num mundo onde a indústria cultural ocupa destacado papel na formação dos indivíduos a semiformação passou a ser a forma dominante da consciência atual.

Mas em quais espaços sociais estamos livres da forte influência dos canais encarregados de reproduzir a semiformação? As políticas de expansão da Educação Superior (e também da Educação Básica), no horizonte histórico do capitalismo, tem como sustentar premissas, por maior que seja a boa vontade dos formadores e dos formados, de uma educação que oportunize uma formação cultural capaz de oferecer-lhes a possibilidade do "esclarecimento"? Acredito que sim, pois nos espíritos mais atentos e curiosos sempre paira a dúvida e a desconfiança que pode levar a descobrir certos arcanos que as consciências menos atentas não conseguem perceber. Penso que são nos interstícios que ocorre a possibilidade da crítica à educação deformadora de nossos tempos. Penso também que é aí que educadores e educandos podem potencializar uma educação para o inconformismo e para a resistência, ainda que o interesse não manifestado nas políticas estatais para a formação docente seja o contrário.

\section{REFERÊNCIAS}

ADORNO, T. Educação - Para Quê? Trad. Wolfgang Leo Maar. In:

Educação e emancipação. 3. ed. São Paulo: Paz e Terra, 2003. p. 139-154.

ADORNO, T. Teoria da Semicultura. In: Revista Educação e Sociedade. Campinas: n. 56, ano XVII, dezembro de 1996, pág. 388-411.

CAPES (Coordenação de Aperfeiçoamento de Pessoal de Nível Superior). Relatório de Gestão (Diretoria de Formação de Professores da Educação Básica DEB), Brasília, 2013.

DEBORD, GUY . A Sociedade do Espetáculo. Rio de Janeiro: Contraponto.1997. 
DUARTE, R. Teoria crítica da indústria cultural. Belo Horizonte: UFMG, 2003.

HORKHEIMER, Max; ADORNO, Theodor. Dialética do Esclarecimento. Rio de janeiro: Jorge Zarhar, 1985.

KANT, Immanuel. Resposta à pergunta: Que é o Iluminismo? In: A paz perpétua e outros opúsculos. Lisboa: Edições 70, 1990

MAAR, W.L. Adorno, Semiformação e Educação. In: Educação e Sociedade. Campinas, vol. 24, n. 83, p. 459-476, agosto 2003.

PUCCI, B. Anotações sobre Teoria e Práxis Educativa. In: PUCCI. Bruno; GOERGEN, Pedro; FRANCO, Renato (Orgs.). Dialética Negativa, Estética e Educação. Campinas: Alínea, 2007, p. 141-152.

SGUISSARDI, Valdemar. Universidade pública estatal: entre o público e privado/mercantil. Educação e Sociedade. 2005, vol.26, n.90, pp. 191-222. 